\title{
25 Research Square \\ First Record of Traumatic Myiasis Obtained From Forest Musk Deer (Moschus Berezovskii) Using DNA Barcoding
}

\section{Yunyun Gao}

Beijing Forestry University https://orcid.org/0000-0003-3389-9385

\section{Yajun Fu}

Beijing Forestry University

\section{Liping Yan}

Beijing Forestry University

Defu Hu

Beijing Forestry University

\section{Benmo Jiang}

Fengxian Fengchun Jimin Credible Science and Technology Breeding Co., Ltd.

Dong Zhang ( $\nabla$ ernest8445@163.com )

College of Ecology and Nature Conservation, Beijing Forestry University, Beijing 100083, China

\section{Research}

Keywords: traumatic myiasis, wild animal, forest musk deer, blowfly

Posted Date: November 17th, 2020

DOl: https://doi.org/10.21203/rs.3.rs-106294/v1

License: (9) (i) This work is licensed under a Creative Commons Attribution 4.0 International License. Read Full License 


\section{Abstract}

Background: Myiasis is a common disease occurring in humans and livestock all over the world. It is closely related to human society and of great significance to animal husbandry, forensic science, and medicine. Myiasis is known to occur in wild animals, while no information is reported in forest musk deer. On July 6, 2019, we found severe traumatic myiasis of an injured forest musk deer (Moschus berezovskii) (Flerov, 1929), infected by lots of maggots and clusters of eggs. However, the precise identification of the larvae that we collected was difficult with few specific morphology characteristics.

Methods: DNA barcoding is an efficient technique for species diagnosis, therefore is employed to identify the samples collected from the infected forest musk deer. Firstly, we extracted genomic DNA from one larva and one egg respectively. The cytochrome oxidase I (COI) gene barcoding region was amplified by polymerase chain reaction (PCR) and bidirectionally sequenced by Sanger sequencing. The sequences were searched for similarity using BLAST and the best hits were Lucilia. To identify these blowflies accurately, these newly generated sequences were subsequently analyzed with COI sequences of Lucilia and Calliphora downloaded from GenBank, to calculate nucleotide divergence, and to construct a neighbor-joining tree.

Results: Our results suggest that nucleotide divergence between the two samples is $0.0033 \mathrm{cM}$, between two samples and Lucilia caesar (Diptera: Calliphoridae) (Linnaeus, 1758) is $0.0016-0.0050 \mathrm{cM}$. Furthermore, the NJ tree construction indicates that the flies collected from the musk deer are Lucilia caesar.

Conclusions: Our results indicate that DNA barcoding can successfully identify pathogenic species. As far as the authors know, this is the first time that myiasis is detected in forest musk deer caused by a traumatic infection in China. The affected individual was clinically treated immediately and apparently recovered.

\section{Background}

Myiasis is a disease caused by dipterous larvae infesting live human or vertebrate animals (Zumpt, 1965). Besides, myiasis not only cause damage, but it also can help people to solve some medicine and forensic medicine problem. Because some myiasis producers also occur on animal wounds and corpses, larvae will eat necrotic tissue to help wounds heal. And forensic specialists can determine the time of death by larvae of flies (Nigam et al. 2006; Vanin et al. 2008). So they have great significance in medicine and forensic medicine as well. It is generally found in human beings and domestic animals (Hall and Wall, 1995; Singh and Singh, 2015). Myiasis agents mainly include larvae of Oestridae, Calliphoridae, Sarcophagidae, and Muscidae (Zumpt, 1965; Hall and Wall, 1995; Pezzi et al. 2019), which has caused major economic obstacle to animal husbandry (Zumpt, 1965; Francesconi and Lup, 2012). However, myiasis is rarely recorded in wild animals due to their being relatively easily hunted or seeking shelters (Hall, 1991; Hall et al., 2016). 
In domestic artiodactyla ruminants such as cattle and sheep, myiasis is very common, which can lead to the death of animals and cause great economic losses (Farkas et al. 1997; Hall, 1997; Francesconi and Lup, 2012; Islam et al. 2015). Wild animals are also susceptible to myiasis due to wound infection by parasitic fly larvae. For example, Huang et al (2016) and Yan et al (2019) found that Przewalski's Horse (Equus ferus przewalskii) (Poliakov, 1881) was highly susceptible to gastric myiasis in the Kalamaili Nature Reserve (KNR) and Xinjiang Research Centre for Breeding Przewalski's Horse, Xinjiang, China. The traumatic myiasis was caused by Wohlfahrtia magnifica (Diptera: Sarcophagidae) (Schiner, 1862). In the 20th century, musk deer (Moschus spp.) cutaneous myiasis was reported in the Sikhote-Alin Mountains, caused by Booponus inexpectatus (Diptera: Calliphoridae) (Grunin, 1947) forming subcutaneous warbles (Rognes, 1998). However, there has been no evidence of myiasis of wild forest musk deer (Moschus berezovskii) in the captive population at present. The forest musk deer we studied are mainly distributed in eastern Asia, especially China. Although they are currently the most abundant musk deer species in China, they are rarely seen in the wild. It has been listed in CITES appendix $\nabla$ and is an endangered animal on the IUCN Red List. Furthermore, it is an important resource animal because adult males secrete musk with high medicinal, economic, and cultural value. At present, captivity is the main strategy for the conservation of forest musk deers (Wang and Sheng, 1988; Yang et al. 2003; Meng et al. 2006).

On July 6, 2019, we found a case of myiasis of forest musk deer in Fengchun Musk Deer Breeding Center. The myiasis of forest musk deer was found to be traumatic. Traumatic myiasis is mainly caused by fly larvae developing in animal decaying tissue after female flies directly laying eggs/larvae at the open wounds of human or animals, resulting in the host wound and surrounding skin to appear swelling, inflammation, pain, and other health problems (Noutsis and Millikan, 1994; Hall, 1997; Yan et al. 2019). Diagnosis and prevention of myiasis are extremely important because myiasis threatens the host health and causes significant economic losses to the livestock industry. At present, the pathogen species of myiasis is mainly diagnosed by morphological and molecular data, sometimes by monoclonal antibodybased enzyme-linked immunosorbent assay (MAb-ELISA) (Azeredo-Espin and Lessinger, 2006; Severini et al. 2015; Pezzi et al. 2015). Herbert et al (2003) suggested that DNA barcodes can be used to identify species, and some Lucilia genus are difficult to morphological identify (Sonet et al, 2012), so we collected larvae and eggs from the wound and fur of the injured forest musk deer for DNA identification. Results showed that the pathogen of myiasis of forest musk deer was the Lucilia caesar (Diptera: Calliphoridae) (Linnaeus, 1758). Since a large number of parasites can seriously affect the host's health and even death, we should pay more attention to the wound healing of forest musk deer and reduce the occurrence of myiasis.

\section{Methods}

All samples were collected from an open wound on the hindquarter of an adult male forest musk deer in Shaanxi Fengxian Fengchun Musk Deer Breeding Center (34¹2'58.07"N, 106 $54^{\prime} 20.93^{\prime \prime} E$, Elevation: $1496 \mathrm{~m}$ ). The wound caused by a fight with male forest musk deer was surrounded by a large number of Calliphoridae larvae (Fig. 1). The maggots and eggs were collected with tweezers and stored in $75 \%$ alcohol (McGraw and Turiansky, 2008) in $4{ }^{\circ} \mathrm{C}$ refrigeration for later use. We treated the musk deer with 
$75 \%$ alcohol disinfection and debridement treatment, and the individual is recovered now. A single larva

and one egg were used to extract DNA respectively with the NucleoSpinTissue XS kit (MACHEREY-NAGEL, Germany). All the extraction was performed in strict accordance with the manufacturer's instructions. DNA was stored at $-20^{\circ} \mathrm{C}$ after DNA extraction. For PCR amplification, $1 \mu \mathrm{L}$ of DNA, $1 \mu \mathrm{L}$ of each COI bidirectional primers $(10 \mu \mathrm{mol} / \mathrm{L}), 12.5 \mu \mathrm{L}$ of $2 \times$ Es Taq MasterMix (Dye) (Beijing Cowin Bioscience Co., Ltd., China), and $9.5 \mu \mathrm{L}$ of Sterile double distilled water were used. PCR primers LC01490: 5'-GGT CAA CAA ATC ATA AAG ATA TTG G-3' and HCO2198: 5'-TAA ACT TCA GGG TGA CCA AAA AAT CA-3' were the same as in Folmer et al. (1994). The PCR procedure was as following: pre-denatured at $95^{\circ} \mathrm{C}$ for $10 \mathrm{~min}$, denatured at $95^{\circ} \mathrm{C}$ for $1 \mathrm{~min}$, annealed at $40^{\circ} \mathrm{C}$ for the $30 \mathrm{~s}$, extended at $72^{\circ} \mathrm{C}$ for 1 min $20 \mathrm{~s}$, a total of 30 cycles, extended again at $72^{\circ} \mathrm{C}$ for $10 \mathrm{~min}$, stored at $4^{\circ} \mathrm{C}$. After amplification, $3 \mu \mathrm{PCR}$ products were used for $1 \%$ Agarose gel (dyed with Goldeview) electrophoresis. The positive product was purified and sent to BGI (Beijing, China) for bidirectionally sequencing following Zhang et al. (2016).

All sequences were edited and trimmed with BioEdit (version 7.0.9.0, Hall, 1999), then assembled by SeqMan 7.1.0 (DNAStar, Steve ShearDown, 1998-2001 version, DNASTAR Inc., USA). MEGA 7 (Kumar et at. 2016) was subsequently used to align sequences, to calculate nucleotide divergence with Kimura's two-parameter (K2P) Model (Kimura, 1980), and to construct a neighbor-joining tree (Saitou and Nei, 1987). Finally, we used the Figtree v1.4.4 (http://tree.bio.ed.ac.uk/software/figtree/) to visualize the NJ tree.

\section{Results}

The COI sequences obtained from the two samples (larva and egg) were $610 \mathrm{bp}$ nucleotides. The two sequences were then searched for similarity using BLAST (Basic Local Alignment Search Tool), compared nucleotide divergence between our samples and flies of Calliphoridae, and constructed phylogenetic tree using MEGA 7.

The consequence showed that the nucleotide divergence between our samples and Lucilia illustris is $0.0117-0.0204 \mathrm{cM}$, between our samples and Lucilia caesar is $0.0016-0.0050 \mathrm{cM}$. The intraspecies variation is $0.16-0.5 \%$, the interspecies variation is $1.17 \%$ (Lucilia caesar to Lucilia illustris) $-8.03 \%$ (Lucilia ampullaceal, Lucilia porphyrina to Calliphora vicina). All sequences were downloaded from NCBI except for sample1 and sample2 (see Additional file 1, Table 1).

Our results of the neighbor-joining phylogenetic tree revealed that different species clade can be clearly distinction. On the other hand, our samples formed a clade with Lucilia caesar with a bootstrap support value $89.8 \%$ (Fig. 2). 
Table 1

$\mathrm{COl}$ gene fragment downloaded from NCBI.

\begin{tabular}{|c|c|c|c|}
\hline Genus & Spcies & Accession & Reference \\
\hline \multirow[t]{22}{*}{ Lucilia } & Lucilia caesar & JX295698.1 & Sonet G. et al \\
\hline & Lucilia caesar & JX295696.1 & Sonet G. et al \\
\hline & Lucilia caesar & JX295695.1 & Sonet G. et al \\
\hline & Lucilia cuprina & KJ129419.1 & Yue. et al \\
\hline & Lucilia cuprina & KJ129418.1 & Yue. et al \\
\hline & Lucilia cuprina & KJ129417.1 & Yue. et al \\
\hline & Lucilia illustris & KJ129550.1 & Yue. et al \\
\hline & Lucilia illustris & KJ129549.1 & Yue. et al \\
\hline & Lucilia illustris & KJ129548.1 & Yue. et al \\
\hline & Lucilia illustris & KJ129547.1 & Yue. et al \\
\hline & Lucilia porphyrina & KM497302.1 & Yue. et al \\
\hline & Lucilia porphyrina & KM497301.1 & Yue. et al \\
\hline & Lucilia porphyrina & KM497300.1 & Yue. et al \\
\hline & Lucilia porphyrina & KM497299.1 & Yue. et al \\
\hline & Lucilia sericata & MN868899.1 & Ferreira S. et al \\
\hline & Lucilia sericata & MN868737.1 & Ferreira S. et al \\
\hline & Lucilia sericata & HQ945054.1 & - \\
\hline & Lucilia sericata & KR521769.1 & Hebert P. et al \\
\hline & Lucilia ampullaceal & KY031826.1 & Yue. et al \\
\hline & Lucilia ampullaceal & KY031825.1 & Yue. et al \\
\hline & Lucilia ampullaceal & KY031824.1 & Yue. et al \\
\hline & Lucilia ampullaceal & KY031823.1 & Yue. et al \\
\hline \multirow{3}{*}{$\begin{array}{l}\text { Calliphora } \\
\text { (outgroups) }\end{array}$} & Calliphora vicina & MN868831.1 & Ferreira S. et al \\
\hline & Calliphora vicina & MN868827.1 & Ferreira S. et al \\
\hline & Calliphora vicina & MN868803.1 & Ferreira S. et al \\
\hline
\end{tabular}




\section{Discussion}

We used BLAST online for searching the similarity sequence based on our two sequences, but the best hits were Lucilia caesar and Lucilia illustris (Meigen, 1826) (Diptera: Calliphoridae). Therefore, we analyzed nucleotide divergence of both samples with the species of Lucilia, and constructed a phylogenetic tree to accurately identify our samples.

Analyses showed that the eggs and larvae that were collected from the wounds of musk deer are the same species (nucleotide divergence is $0.0033 \mathrm{cM}$ ). Our results indicate the flies collected from the forest musk deer are Lucilia caesar. Boehme et al (2012) suggested that the intraspecies difference of COI barcode for Lucilia caesarwas lower than $1.17 \%$, and the interspecies difference of COI barcode between Lucilia caesar and Lucilia illustris is $1.17 \%-1.96 \%$. The nucleotide divergence between our samples and Lucilia illustris is $0.0117-0.0204 \mathrm{cM}$, between our samples and Lucilia caesar is $0.0016-0.0050 \mathrm{cM}$. Furthermore, our samples are supported to be sitting together with Lucilia caesar. Therefore, we considered that the fly larvae and eggs causing traumatic myiasis of the forest musk deer were Lucilia caesa from the molecular point of view.

The difference between Lucilia caesarand Lucilia illustris using COI is difficult, cause they share at least one genotype or haplotype on this fragment (Sonet et al, 2012; Williams et al, 2016). However, they prefer different habitats. In Britain and Switzerland, Lucilia caesar prefer forest and shade environment, while Lucilia illustris prefer open forest, grasslands, and sunny areas. Therefore, the habitat environment of the fly can be used as a reasonable reference for identification of these species (Arias-Robledo et al, 2019).

Lucilia caesar mainly distribute in the Palaearctic region (Zumpt, 1965), widely distributed in Xinjiang, Inner Mongolia, Shaanxi, Gansu, and other places in China (www.zoology.csdb.cn/). Female flies are easily attracted to the smell of decaying tissue and lay eggs on it. The larvae mainly parasitize on animal wounds or sloughs and often cause traumatic myiasis, which is one of the main pathogens of sheep myiasis in northern Europe (Hall, 1997). We found the case on July 6, 2019, at the Fengchun Musk Deer Breeding Center, which is located in the Qinling Mountains with dense forest and an altitude of 1496 meters. At the time of this case, it's summer with relatively high temperature, rainy, and humid, which is more in line with the habitat of the Lucilia caesarthan Lucilia illustris, the latter often found in open and warm areas close to human. Taken together the clues from habitat and DNA barcode, the fly larvae and eggs found from the wound of forest musk deer are Lucilia caesar.

\section{Conclusion}

So far, there is little research on traumatic myiasis in China and even less on traumatic myiasis in wild animals, but this disease has a serious impact on animal welfare and the economics of livestock breeding (Hall and Wall, 1995). At present, the main control strategies for myiasis are light trapping, conventional chemical control (Yan et al. 2019), insecticidal applications, crutching, and so on (Hall, 1997). However, for the long-term health of captive animals, we should pay more attention to predicting 
the possible distribution range and occurrence time of parasitic flies based on their current distribution and adaptive environmental types. Besides, attention should be paid to the health status of the animals themselves, promptly debride and nurse animal wounds, avoid phenomenon such as wound infection, decay, and so on. Finally, we should consider both parasitic flies and hosts to reduce the incidence of myiasis and achieve the purpose of protecting wild animals.

\section{Abbreviations}

$\mathrm{COI}$

cytochrome oxidase I

PCR

polymerase chain reaction

MAb-ELISA

monoclonal antibody-based enzyme-linked immunosorbent assay

$\mathrm{K} 2 \mathrm{P}$

Kimura's two parameter

\section{Declarations}

\section{Ethics approval and consent to participate}

The sample collection of this study was progressed smoothly with the approval of Nature Conservation, Beijing Forestry University, the guidelines of the Institution of Animal Care and the Ethics Committee of Beijing Forestry University, and the help of local veterinarians.

\section{Consent for publication}

Not applicable

\section{Availability of data and materials}

Not applicable

\section{Competing interests}

The authors declare that they have no competing interests

\section{Funding}

This study was supported by the Fundamental Research Funds for the Central Universities (No. 2019ZY46囚No. 2019YC01).

\section{Authors' contributions}


Yunun Gao, Benmo Jiang collected samples, Dong Zhang, Defu Hu and Yunyun Gao design experiments, Yunyun Gao and Yajun Fu performed molecular experiments. Yajun Fu, Yunyun Gao and Liping Yan analyzed experiment results. Yajun Fu, Yunun Gao, Liping Yan, Defu Hu, Benmo Jiang and Dong Zhang joined writing the manuscript. All authors read and approved the final manuscript.

Yunyun Gao and Yajun Fu contributed equally to this paper.

\section{Acknowledgements}

We are grateful to Kun Yang and Gang Jiang (Fengchun Musk Deer Breeding Center, Shaanxi) for their efforts in the field work.

\section{Authors' information}

Affiliations

${ }^{1}$ School of Ecology and Nature Conservation, Beijing Forestry University, Beijing, 100083, China

${ }^{2}$ Fengxian Fengchun Jimin Credible Science and Technology Breeding Co., Ltd., Shaanxi, 721000, China

\section{Corresponding authorn}

Correspondence to Dong Zhang.

\section{References}

1. Azeredo-Espin AM, Lessinger AC. Genetic approaches for studying myiasis-causing flies: molecular markers and mitochondrial genomics. Genetica. 2006;126:111-31.

2. Arias-Robledo G, Stevens JR, Wall R. Spatial and temporal habitat partitioning by calliphorid blowflies. Med Vet Entomol. 2019;33:228-37.

3. Boehme P, Amendt J, Zehner R. The use of COI barcodes for molecular identification of forensically important fly species in Germany. Parasitol Res. 2012;110:2325-32.

4. Farkas R, Hall MJR, Kelemen F. Wound myiasis of sheep in Hungary. Vet Parasitol. 1997;69:133-44.

5. Folmer O, Black MB, Hoeh WR, Lutz RA, Vrijenhoek RC. DNA primers for amplification of mitochondrial cytochrome c oxidase subunit I from diverse metazoan invertebrates. Mol Mar Biol Biotech. 1994;3:294-9.

6. Francesconi F, Lupi O. Myiasis. Clinical microbiology reviews. 2012; 25: 79-105.

7. Hall TA. BioEdit: a user-friendly biological sequence alignment editor and analysis program for Windows 95/98/NT. Nucleic Acids Symp Ser. 1999;41:95-8.

8. Hall MJR. Screwworm flies as agents of wound myiasis. Revue Mondiale de Zootechnie (FAO); Revista Mundial de Zootecnia (FAO).1991.

9. Hall MJR. Wall R. Myiasis of humans and domestic animals. Adv Parasitol. 1995;35:257-334. 
10. Hall MJR. Traumatic myiasis of sheep in Europe: a review. Parassitologia. 1997;39:409-13.

11. Hall MJR, Wall RL, Stevens JR. Traumatic myiasis: a neglected disease in a changing world. Annual Review Entomology. 2016;61:159-76.

12. Hebert PDN, Cywinska A, Ball SL, Dewaard JR. Biological identifications through DNA barcodes. Proceedings of The Royal Society B: Biological Sciences. 2003; 270: 313-321.

13. Huang H, Zhang B, Chu H, Zhang D, Li K. Gasterophilus (Diptera, Gasterophilidae) infestation of equids in the Kalamaili Nature Reserve, China. Parasite. 2016;23:36.

14. Islam MT, Maruf AA, Mannan MA, Rahman HMR, Tarafder MM, Samad MA, et al. Isolation and identification of associated bacteria and maggots from myiasis affected wounds of cattle and goats in Bangladesh. Journal of Advanced Veterinary Animal Research. 2015;2:95-100.

15. Katoh K, Standley DM. MAFFT Multiple Sequence Alignment Software Version 7: Improvements in performance and usability. Mol Biol Evol. 2013;30:772-80.

16. Kimura M. A simple method for estimating evolutionary rate of base substitutions through comparative studies of nucleotide sequences. J Mol Evol. 1980;16:111-20.

17. Kumar S, Stecher G, Tamura K. MEGA7: Molecular Evolutionary Genetics Analysis version 7.0 for bigger datasets. Mol Biol Evol. 2016;33:1870-4.

18. McGraw TA, Turiansky GW. Cutaneous myiasis. J Am Acad Dermatol. 2008;58:907-26.

19. Meier R, Shiyang K, Vaidya G, Ng PKL. DNA Barcoding and taxonomy in Diptera: a tale of high intraspecific variability and low identification success. Syst Biol. 2006;55:715-28.

20. Meng X, Zhou C, Hu J, Cao L, Meng Z, Feng J, et al. Musk deer farming in China. Anim Sci. 2006;82(1):1-6.

21. Noutsis C, Millikan LE. Myiasis Dermatol Clin. 1994;12:729-36.

22. Nigam Y, Bexfield A, Thomas S, Ratcliffe NA. Maggot therapy: the science and implication for CAM Part I-history and bacterial resistance. Evidence-based complementary Alternative Medicine. 2006;3:223-7.

23. Pezzi M, Whitmore D, Chicca M, Lanfredi M, Leis M. Traumatic myiasis caused by an association of Sarcophaga tibialis (Diptera: Sarcophagidae) and Lucilia sericata (Diptera: Calliphoridae) in a domestic cat in Italy. Korean J Parasitol. 2015;53(4):471-5.

24. Pezzi M, Bonacci T, Leis M, Mamolini E, Marchetti MG, Krcmar S, et al. Myiasis in domestic cats: a global review. Parasites Vectors. 2019;12:1-14.

25. Rognes K. Family Calliphoridae. In: Contributions to a Manual of Palaearctic Diptera Volume 3: Higher Brachycera. Budapest: Science Herald; 1998. pp. 617-48.

26. Saitou N, Nei M. The neighbor-joining method: A new method for reconstructing phylogenetic trees. Mol Biol Evol. 1987;4:406-25.

27. Severini F, Nocita E, Tosini F. Myiasis of the tracheostomy wound caused by Sarcophaga (Liopygia) argyrostoma (Diptera: Sarcophagidae): molecular identification based on the mitochondrial cytochrome c oxidase I gene[J]. J Med Entomol. 2015;52(6):1357-60. 
28. Singh A, Singh Z. Incidence of myiasis among humans-a review. Parasitol Res. 2015;114:3183-99.

29. Sonet G, Jordaens K, Braet Y, Desmyter $S$. Why is the molecular identification of the forensically important blowfly species Lucilia caesarand L. illustris (family Calliphoridae) so problematic? Forensic Sci Int. 2012;223:153-9.

30. Vanin S, Tasinato P, Ducolin G, Terranova C, Zancaner S, Montisic M, et al. Use of Lucilia species for forensic investigations in Southern Europe. Forensic Sci Int. 2008;177:37-41.

31. Wang $\mathrm{H}$, Sheng $\mathrm{H}$. Studies on population densites, conservation and exploitation of forest musk deer (Moschus berezovskii) in the northwest of the Sichuan basin. Acta Theriologica Sinica. 1988; 8.

32. Williams KA, Lamb JM, Villet MH. Phylogenetic radiation of the greenbottle flies (Diptera, Calliphoridae, Luciliinae). ZooKeys. 2016;568:59-86.

33. Yan L, Zhang M, Tang L, Ente M, Ma X, Chu H, et al. First reports of nasal and traumatic myiasis infection in endangered Przewalski's horses (Equus ferus przewalskii). International Journal for Parasitology: Parasites Wildlife. 2019;9:21-4.

34. Yang Q, Meng X, Xia L, Feng Z, et al. Conservation status and causes of decline of musk deer (Moschus spp.) in China. Biol Cons. 2003;109:333-42.

35. Zhang D, Yan L, Zhang M, Chu H, Cao J, Li K, et al. Phylogenetic inference of calyptrates, with the first mitogenomes for Gasterophilinae (Diptera: Oestridae) and Paramacronychiinae (Diptera:

Sarcophagidae). International Journal of Biological Sciences. 2016;12:489-504.

36. Zumpt F. Myiasis in man and animals in the old world. London: Butterworths; 1965.

37. Molecular evolution. phylogenetics and epidemiology. http://tree.bio.ed.ac.uk/software/figtree/. Accessed 14 Jul 2020.

38. China Animal Scientific Database.http://www.zoology.csdb.cn/. Accessed 15 Jul 2020.

\section{Figures}




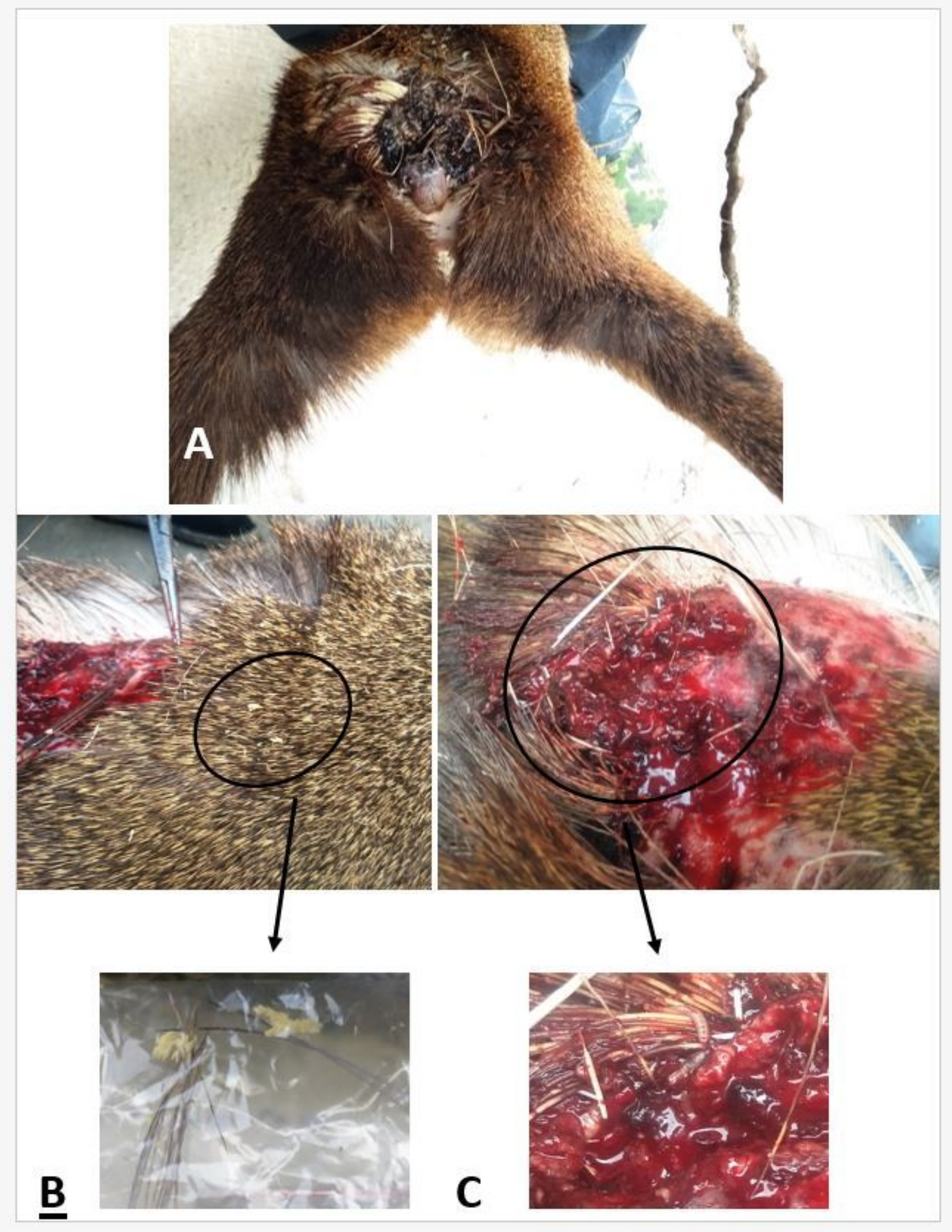

\section{Figure 1}

A picture of myiasis found in an open wound of male Forest Musk Deer. This Forest Musk Deer is breeding in Shaanxi Fengxian Fengchun Musk Deer Breeding Center. The wound is oval, located on Forest Musk Deer hindquarter. There were many larvae and eggs of Calliphoridae discovered at the wound and caused serious traumatic myiasis. 


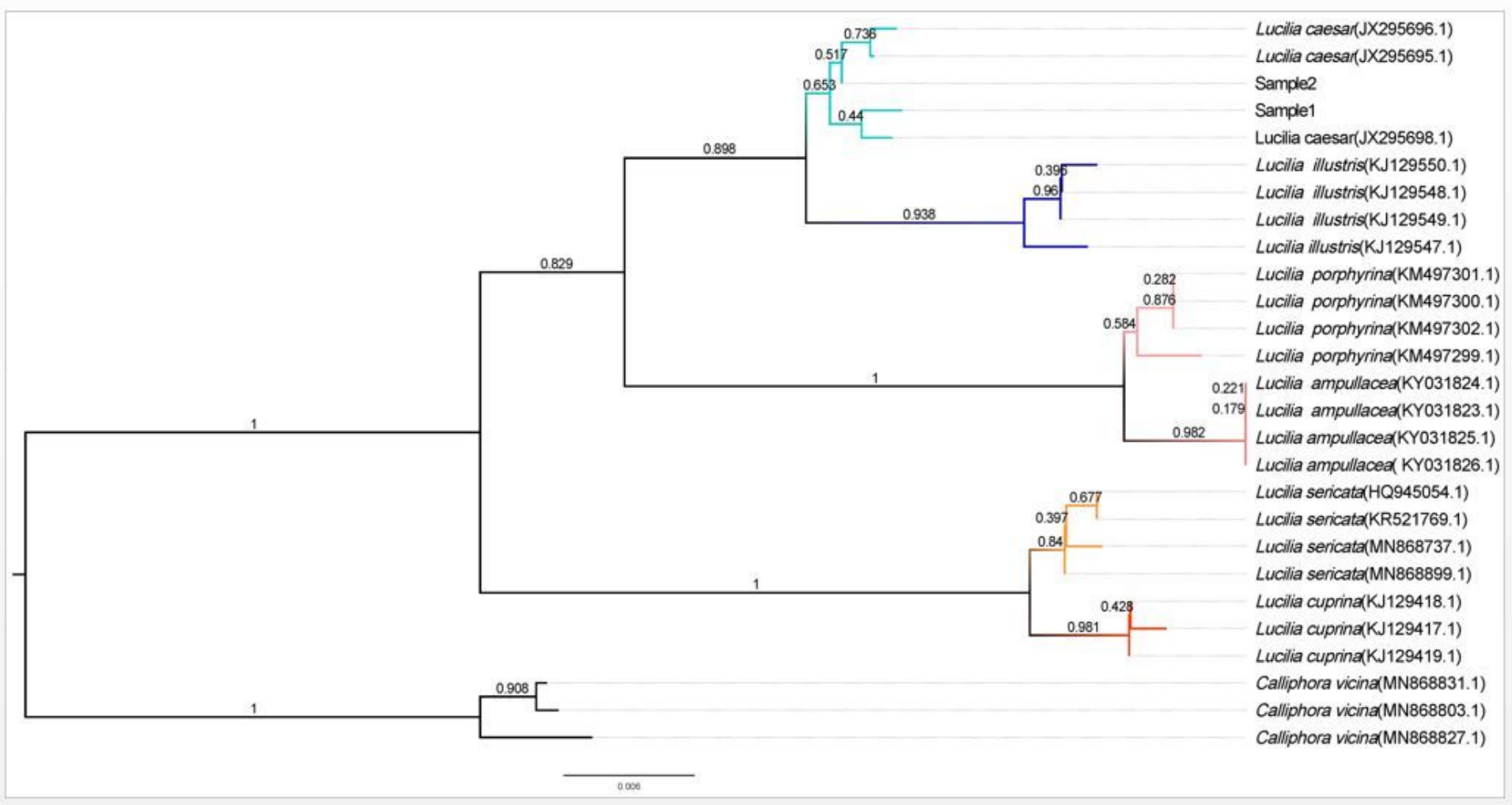

Figure 2

Neighbor-joining tree (1000 bootstrap replicates) of analyzed species. The evolutionary history was inferred using the Neighbor-Joining method based on the Kimura 2-parameter model. The tree is drawn to scale, and using the number of substitutions per site to measured branch lengths. The analysis involved 27 nucleotide sequences. All ambiguous positions were removed for each sequence pair. There were a total of 717 positions in the final dataset. Evolutionary analyses were conducted in MEGA7. The bootstrap supports of Lucilia caesar and Lucilia illustris is $89.8 \%$.

\section{Supplementary Files}

This is a list of supplementary files associated with this preprint. Click to download.

- Additionalfile.xls 